\title{
Complex interventions required to comprehensively educate allied health practitioners on evidence-based practice
}

This article was published in the following Dove Press journal:

Advances in Medical Education and Practice

5 May 201I

Number of times this article has been viewed

\author{
Janine Margarita Dizon ${ }^{1,2}$ \\ Karen Grimmer-Somers' \\ 'International Centre for Allied \\ Health Evidence, University of South \\ Australia, Adelaide, SA, Australia; \\ ${ }^{2}$ University of Santo Tomas, Manila, \\ Philippines
}

\begin{abstract}
There is currently no strong evidence regarding the most effective training approach for allied health professionals that will support them to consistently apply the best research evidence in daily practice. Current evidence-based practice training tends to be 'one size fits all', and is unlikely to be appropriate for all allied health disciplines because of the variability in their tasks and scope of practice. The scant body of evidence regarding the effectiveness of evidence-based practice training for allied health practitioners provides some support for improving knowledge and skills, but equivocal evidence about influencing behaviors and attitudes. We propose a new model of evidence-based practice training, based on the concept of complex interventions reported in the literature. We believe that by offering training in evidence-based practice based on complex interventions relevant to the needs of the attendees, using fixed and variable components, there may be greater success in significantly influencing knowledge skills, attitudes, and behaviors.
\end{abstract}

Keywords: complex interventions, evidence-based practice training, allied health

\section{Background}

Allied health (AH) is an umbrella term used to define a large collection of different health disciplines that have complex and interrelated roles, responsibilities, skills, and scopes of practice. Allied health basically covers all those health professions that are not medical, nursing, or dentistry. Turnbull et al described the complexities of AH using a three-dimensional model. ${ }^{1}$ This model reflects tasks and roles as two dimensions (discipline-specific, and shared between disciplines), and skills escalation as the third dimension. Grimmer and Kumar further described the complexity of tasks undertaken by AH professionals even within the one discipline (for instance a physiotherapist might screen for risk factors, diagnose, educate, treat, manufacture, and counsel the one patient, or may undertake one task only for a number of different patients). ${ }^{2}$ They also addressed the importance of providing the best evidence for each type of task by using task-appropriate research designs. They highlighted the importance of discipline-specific journals to publish papers appropriate to all tasks undertaken by the discipline (for instance, research not only on the effectiveness of different treatments, but also research on screening, assessing for risk factors for poor outcome, diagnostic studies, and quality improvement).

There has been increasing interest over the past decade in educating $\mathrm{AH}$ professionals about evidence-uptake into practice. However our recent systematic literature review identified only six studies that examined the effectiveness of evidence-based practice (EBP) training, three reporting on a combination of health 
professionals such as doctors, nurses, health managers, and $\mathrm{AH}$ professionals; ${ }^{3-5}$ and three specific $\mathrm{AH}$ disciplines (physiotherapy, ${ }^{6}$ occupational therapy, ${ }^{7}$ and social work ${ }^{8}$ ). ${ }^{9}$ EBP training outcomes were generally described as changes in at least one of these four EBP domains (knowledge, skills, attitudes, and behaviors). ${ }^{10,11}$ Significant improvements in knowledge and skills in EBP were reported in all studies, resulting from relatively short duration training sessions, however, there was limited and equivocal evidence of change in attitudes and behavior. We could not determine whether this was because of the timing and method of measurement, or specific training strategies, or the type of AH professional being educated. We subsequently suggested the need for longer duration periods of measurement, discipline-specific outcome measures, and different types of training appropriate to specific $\mathrm{AH}$ disciplines, to significantly and sustainably improve EBP attitudes and behaviors.

This paper is a reflection of the findings of our systematic review in relation to issues associated with training $\mathrm{AH}$ professionals in EBP, particularly the training required to change their attitudes and behaviors towards research evidence implementation. We propose that there are key issues to consider when designing effective EBP training programs for AH practitioners, including:

- Allied health disciplines differ in terms of their contexts and scope of practice, their clinical training, and the research that matters to their day-to-day practice.

- EBP training appears to currently be 'one-size-fits-all' (we have found no programs tailored for the specific tasks of any one AH discipline) and we question whether this generalist approach is effective, efficient, or acceptable to adult learners. We contend that different training approaches may be required in order to produce significant and sustainable change in all EBP domains.

- Different types of training may be required to assist practitioners from different $\mathrm{AH}$ disciplines to learn how to set and answer questions relevant to their core tasks and responsibilities. We suggest that these may include effectiveness questions for treatment tasks, diagnosis questions for diagnostic tasks, screening questions for screening, and monitoring tasks.

\section{Discussion}

Given the complexity of $\mathrm{AH}$ care, it is unlikely that training programs in EBP produced for other health professions will be readily or directly applied to $\mathrm{AH}$ disciplines. It is also unlikely that even a 'one-size-fits-all' training program developed for $\mathrm{AH}$ needs will be appropriate for every
AH discipline. The concept of 'evidence of fit in complex interventions ${ }^{\prime 2}$ presents an appropriate model to underpin our reflections on what might be more effective training approaches to deal with specific $\mathrm{AH}$ requirements. Only by considering EBP training strategies in the context of $\mathrm{AH}$ discipline roles, responsibilities, tasks, practice settings, referral mechanisms, and practice restrictions, will every $\mathrm{AH}$ professional who attends EBP training be assured of learning something of value that will influence his/her practice in the short-term as well as longer term.

There is also an increasing body of literature on implementation science, which highlights the need for multipronged approaches to ensure sustainable implementation of evidence into health practices. ${ }^{13,14}$ The majority of the implementation studies have been conducted in medicine, mostly concentrating on the implementation of guidelines. ${ }^{15-19}$ Effective strategies include multi-pronged ways of delivering EBP messages, coupled with peer support, and feedback over a sufficiently long time period to support change in thinking and behaviors. Practice visits and mentoring, and easy-to-navigate sources of information are also useful. There has been little research into evidence implementation in $\mathrm{AH}$, however it is unlikely to present a different scenario to medicine.

The Medical Research Council's concept of complex interventions ${ }^{20}$ and Hawe and colleagues' work ${ }^{12}$ regarding standardizing complex interventions by considering the interventions as fixed (core, constant) components and variable components lead us to suggest that EBP training should be similarly considered, as a complex intervention, with fixed and variable aspects. Fixed aspects of training could address general skill and knowledge acquisition related to core EBP principles. These should be relevant to any AH discipline, even considering the different tasks they undertake. The variable components of training should address complex issues such as practice settings, patient-types, disciplinespecific contexts, multiple roles performed by the one health provider for one patient, as well as multi-professional practice where health care providers from different disciplines need to interact in the management of one patient. We believe that the model presented by Hawe and colleagues, ${ }^{12}$ can be used to present an appropriate framework for effective EBP training for any $\mathrm{AH}$ discipline.

We based Table 1 on Hawe's approach, and propose principles of education for EBP for allied health. These principles reflect core (standard) needs for EBP training, and also embrace the variable requirements related to the complexity of what AH professionals may do in day-to-day practice. 
Table I Standardizing EBP training for allied health

\begin{tabular}{|c|c|c|}
\hline $\begin{array}{l}\text { Categories to summarize and } \\
\text { standardize components of the } \\
\text { interventions }\end{array}$ & Forms related to the components & EBP domains addressed \\
\hline \multicolumn{3}{|l|}{ Constant/fixed aspects } \\
\hline - Essential components/functions & $\begin{array}{l}\text { - Teaching the concepts of EBP } \\
\text { - Teaching the steps to EBP (Question formulation, searching and } \\
\text { appraising the evidence) } \\
\text { - Teaching the concepts and steps to EBP using lecture-demonstration } \\
\text { with practical sessions format }\end{array}$ & Knowledge and skills \\
\hline \multicolumn{3}{|l|}{ Variable aspects } \\
\hline $\begin{array}{l}\text { The form in different contexts mapped to } \\
\text { the characteristics of the population and the } \\
\text { local setting }\end{array}$ & $\begin{array}{l}\text { - Teaching formulation of question in line with the AH discipline } \\
\text { (based on Turnbull } 2009 \text { classification), ie, effectiveness question } \\
\text { for the allied health therapy group; diagnostic question for the } \\
\text { - Exploratory analysis of practice context with a local steering } \\
\text { committee or key informants } \\
\text { - Assessment of resources to use (computers, internet connection, } \\
\text { access to databases, and freely available resources) } \\
\text { - Use of opinion leaders } \\
\text { - Provision of readily accessible learning materials (paper vs } \\
\text { electronic files) } \\
\text { - Provision of follow up support to address lack of time and access } \\
\text { barriers }\end{array}$ & Attitudes and behavior \\
\hline
\end{tabular}

Abbreviation: EBP, evidence-based practice.

The core or fixed elements of training would seem to be those required to change knowledge and skills in EBP. These domains could be addressed in short-duration training, given in a standard manner to all AH professionals. The curriculum could include the steps to $\mathrm{EBP},{ }^{4}$ an overview of the different research designs relevant to $\mathrm{AH}$ tasks, ${ }^{2}$ and how to critically appraise, read, and understand different research design studies. $^{21,22}$ This training could also address in a general sense, implementation barriers likely to be faced by $\mathrm{AH}$ professionals when implementing evidence into daily practice. ${ }^{19}$

The variable elements of training would relate to the specifics of AH disciplines practice and the sustainable application of evidence into practice. The variable training components would be more designed to influence attitudes and behaviors by matching discipline-specific EBP needs with complex training interventions, which would include appropriate skills and a range of supports. For instance, teaching the EBP process to a professional in the AH diagnostic and technical group ${ }^{1}$ should focus on diagnostic question formulation and the specific types of primary and secondary research evidence that would answer the question. ${ }^{21}$ This will require very different training to that given to a therapist whose primary focus is on treatment. ${ }^{1,2}$

Complex interventions are deliberately-initiated attempts to introduce new, or modify existing patterns of collective action in health care. ${ }^{23}$ These types of interventions can range from interventions designed to set up new health care systems, to interventions developed and tested to adapt and implement evidence into practice, to educational interventions for the whole community. Thus, EBP training provided to $\mathrm{AH}$ professionals that focuses on changing attitudes and behaviors, could include multifaceted interventions which incorporate strategies such as practicing the skills as guided by leaders, use of audit and feedback to enhance the use of the intervention, and follow-up support to facilitate changes in attitudes and behavior. ${ }^{13}$ Context level adaptation, which is designing a program to suit an individual participant's needs, ${ }^{12}$ could be the key for training interventions to facilitate sustainable $\mathrm{AH}$ behavior change.

\section{Recommendations}

We outline our concept in Table 1, using Hawe and colleague's approach. ${ }^{12}$

We suggest that by taking this approach to designing AH EBP training programs, educators can maximize the training opportunities being provided to the AH professionals attending training, and ensure that training time is well spent. Educators will also be better prepared to deliver material suited to the needs of the adult learning class, and EBP training that is delivered in a manner that improves its implementation and sustainability. Ensuring appropriate EBP training relevant to the needs of $\mathrm{AH}$ will assist in improved and sustainable uptake of evidence into daily practice. 


\section{Disclosure}

The authors declare no conflicts of interest in this work.

\section{References}

1. Turnbull C, Grimmer-Somers K, Kumar S, May E, Law D, Ashworth E. Allied, scientific and complementary health professionals: a new model for Australian allied health. Aust Health Rev. 2009;33:27-37.

2. Grimmer K, Kumar S. Allied health task-related evidence. J Soc Work Res. 2005;6:143-154.

3. Villanueva EV, Burrows EA, Fennessy PA, Rajendran M, Anderson JN. Improving question formulation for use in evidence appraisal in a tertiary care setting: a randomised controlled trial. BMC Med Inform Decis. 2001;1:4.

4. Cheng GY. Educational workshop improved information-seeking skills, knowledge, attitudes and the search outcome of hospital clinicians: a randomised controlled trial. Health Info Libr J. 2003;20(Suppl 1):22-33.

5. Taylor RS, Reeves BC, Ewings PE, Taylor RJ. Critical appraisal skills training for health professionals: a randomized controlled trial. $B M C$ Med Educ. 2004;4:30.

6. Stevenson K, Lewis M, Hay E. Do physiotherapists' attitudes towards evidence-based practice change as a result of an evidence-based educational programme? J Eval Clin Pract. 2004;10:207-217.

7. McCluskey A, Lovarini M. Providing education on evidence-based practice improved knowledge but did not change behaviour: a before and after study. BMC Med Educ. 2005;5:40.

8. Parrish D, Rubin A. An effective model for continuing education training in evidence-based practice. Res Social Work Prac. 2010;21:77-87.

9. Dizon JMR, Grimmer-Somers K, Kumar S. Systematic review of the effectiveness of EBP educational programs in enhancing knowledge, attitudes, skills and behaviour of allied health practitioners. In Proceedings of the 11th International Congress of the Asian Confederation for Physical Therapy, Conference 10-13 October: Bali, Indonesia; 2010.

10. Coomarasamy A, Khan KS. What is the evidence that postgraduate teaching in evidence-based medicine changes anything? A systematic review. BMJ. 2004;329:1017-1022.

11. Dawes M, Summerskill W, Glasziou P, et al. Sicily statement on evidence-based practice. BMC Med Educ. 2005;5:1.
12. Hawe P, Shiell A, Riley T. Complex interventions: how "out of control" can a randomized controlled trial be? BMJ. 2004;328:1561-1563.

13. Thomson O'Brien MA, Freemantle N, Oxman AD, Wolf F, Davis DA, Herrin J. Continuing education meetings and workshops: effects on professional practice and health care outcomes (review). The Cochrane Database of Systematic Reviews. 2001;(2):CD003030.

14. Mendel P, Meredith L, Schoenbaum M, Sherbourne C, Wells K. Interventions in organizational and community context: a framework for building evidence on dissemination and implementation in health services research. Adm Policy Ment Health. 2008;35:21-37.

15. Grimshaw JM, Shirran L, Thomas R, et al. Changing provider behavior: an overview of systematic reviews of interventions. Med Care. 2001; 39(8 Suppl 2):112-145.

16. Grimshaw J, Eccles M, Walker A, Thomas R. Changing physicians' behavior: what works and thoughts on getting more things to work. J Contin Educ Health. 2002;22:237-243.

17. Grol R, Grimshaw J. From best evidence to best practice: effective implementation of change in patients' care. The Lancet. 2003;362: $1225-1230$.

18. Grimshaw J, Eccles M, Tetroe J. Implementing clinical guidelines: current evidence and future implications. J Contin Educ Health. 2004;24:31-37.

19. Grol R, Wensing M. What drives change? Barriers to and incentives for achieving evidence-based practice? Med J Australia. 2004;180:57-60.

20. Medical Research Council Health Services and Public Health Research Board. A Framework for Development and Evaluation of RCTS for Complex Interventions to improve health; 2000.

21. Merlin T, Weston A, Tooher R. Extending an evidence hierarchy to include topics other than treatment: revising the Australian 'levels of evidence'. BMC Med Res Methodol. 2009;9:34.

22. Sackett DL, Straus SE, Richardson SW, Rosenberg W, Haynes BR. Evidence-based medicine. Philadelphia, PA: Churchill Livingstone; 2000.

23. May C, Finch T, Mair F, et al. Understanding the implementation of complex interventions in health care: the normalization process model. BMC Health Serv Res. 2007; 7:148.
Advances in Medical Education and Practice

\section{Publish your work in this journal}

Advances in Medical Education and Practice is an international, peerreviewed, open access journal that aims to present and publish research on Medical Education covering medical, dental, nursing and allied healthcare professional education. The journal covers undergraduate education, postgraduate training and continuing medical education

\section{Dovepress}

including emerging trends and innovative models linking education, research, and healthcare services. The manuscript management system is completely online and includes a very quick and fair peer-review system. Visit http://www.dovepress.com/testimonials.php to read real quotes from published authors. 